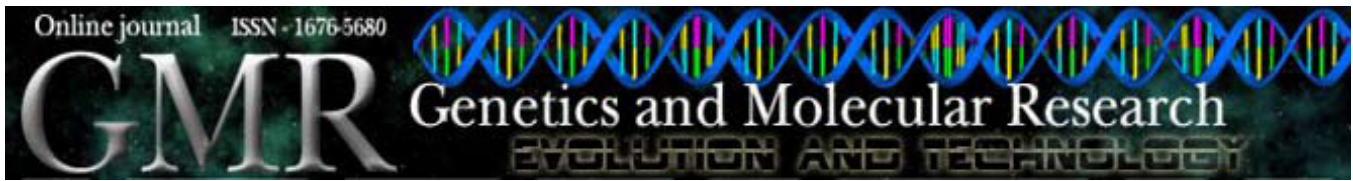

\title{
Association of CAPN1 316, CAPN1 4751 and TG5 markers with bovine meat quality traits in Mexico
}

\author{
C.A. Bonilla ${ }^{4}$, M.S. Rubio ${ }^{1}$, A.M. Sifuentes ${ }^{2}$, G.M. Parra-Bracamonte ${ }^{2}$, \\ V.W. Arellano ${ }^{2}$, M.R.D. Méndez ${ }^{1}$, J.M. Berruecos ${ }^{1}$ and R. Ortiz ${ }^{3}$ \\ ${ }^{1}$ Laboratorio de Ciencia de la Carne, Secretaría de Producción Animal, \\ Facultad de Medicina Veterinaria y Zootecnia, \\ Universidad Nacional Autónoma de México, Ciudad Universitaria, México \\ ${ }^{2}$ Laboratorio de Biotecnología Animal, Centro de Biotecnología Genómica, \\ Instituto Politécnico Nacional, Tamaulipas, México \\ ${ }^{3}$ Unidad de Diagnóstico Molecular, Universidad Autónoma de Nuevo León, \\ Monterrey, Nuevo León, México \\ ${ }^{4}$ Consejo Nacional de los Recursos Genéticos Pecuarios A.C., México, D.F. \\ Corresponding author: M.S. Rubio \\ E-mail:msalud@servidor.unam.mx
}

Genet. Mol. Res. 9 (4): 2395-2405 (2010)

Received August 24, 2010

Accepted September 20, 2010

Published December 14, 2010

DOI 10.4238/vol9-4gmr959

ABSTRACT. We examined allele and genotype frequencies for the molecular markers CAPN1 316, CAPN1 4751 and TG5, and determined whether they are associated with beef quality traits in Mexican cattle. One hundred and twenty-four longissimus dorsi muscle samples were collected from cattle from north, central and southern Mexico. CAPN1 316 and CAPN1 4751 frequencies were determined using the allelic discrimination assay and the TG5 marker was typed by PCR-RFLP. Meat quality traits included intramuscular fat content (IMF) and tenderness determined by Warner-Bratzler shear force (WBSF) at $24 \mathrm{~h}$ postmortem. The association test was made using a mixed model, including genotypes, genetic group, and sampling location as fixed effects. Least squares means and significant interactions were compared using least significant differences based on the mixed procedure. CAPN1 $316 \mathrm{CC}$ was found 
at a low frequency $(0.03)$ and has been reported as a favorable genotype associated with tenderness meat. Genotype frequencies for CAPN1 4751 were similar in favorable (CC) and unfavorable (TT) genotypes ( 0.26 and 0.28 , respectively). The TG5 CC genotype had a frequency of 0.73 , while the TT genotype frequency was 0.01 . The means for WBSF and IMF were $4.08 \pm 1.35 \mathrm{~kg}$ and $5.23 \pm 2.14 \%$, respectively. Sampling site and the CAPN1 316 genotypes significantly affected WBSF $(P<0.05)$. Samples collected from Hermosillo, Sonora, had the lowest WBSF $(\mathrm{P}<0.05)$, while those collected in Veracruz were toughest $(\mathrm{WBSF}=5.267 \mathrm{~kg})$. The effect of GG and TG5 genotypes on IMF was significant $(\mathrm{P}<0.05)$. CAPN1 316 and TG5 markers were found to be significantly associated with beef quality traits and thus will be useful for Mexican beef characterization.

Key words: Molecular markers; Bovine meat quality; Intramuscular fat; Warner-Bratzler shear force; CAPN1; TG5

\section{INTRODUCTION}

In Mexico the beef industry faces some problems and meat quality inconsistency is one of the greatest. It is caused by the lack of strategies to produce cattle with constant and defined traits (Ruíz et al., 2004).

Traditionally, genetic improvement has been done on the basis of observable phenotype traits and the use of estimated breeding values. Nowadays, improvement strategies include the use of molecular markers to assist genetic selection and management of carrieranimals for favorable allelic variants associated with quantitative traits difficult or expensive to measure, such as the meat quality traits, in particular tenderness and marbling (Meuwissen and Goddard, 1996; Van Eenennaam et al., 2007).

To date several markers have been developed to predict quality traits in beef cattle. The micromolar calcium-activated neutral protease (CAPN1) is encoded by the CAPN1 gene and 3 markers (CAPN1 316, CAPN1 4751 and CAPN1 530) have been developed in this gene that are associated with meat tenderness (Page et al., 2002, 2004; White et al., 2005; Casas et al., 2005, 2006). The TG5 marker (thyroglobulin 5 ' leader sequence) is a single-nucleotide polymorphism (SNP) that has been associated with marbling (Barendse et al., 2004; Barendse, 2005). TG5, CAPN1 316 and CAPN1 4751 markers have been included in some commercial DNA-tests (GeneSTAR and Igenity TenderGENE) engineered to predict productive traits. Even when Van Eenennaam in 2007 reported, in a study, on the validation of these available tests, there are conflicting reports in the literature regarding the association of CAPN1 and TG5 markers with tenderness and marbling, respectively. Therefore, the worldwide commercial use of these DNA tests is conditioned by their validation in different breeds of cattle and environments (Barendse, 2005).

One of the main requirements in order to achieve association between a molecular marker and a specific trait is the integration of a database with quantitative measures. This is expensive and not easy to achieve in traits such as meat quality. In Mexico, beef producers are in no position to generate such phenotypic data.

The aim of this study was to determine the allelic and genotypic frequencies of CAPN1 316, CAPN1 4751 and TG5 markers and assess their association with Mexican meat quality traits. 


\section{MATERIAL AND METHODS}

One hundred and twenty-four samples $(2.54 \mathrm{~cm}$ from the longissimus dorsi muscle (LM) area between the 12th and 13th rib) were collected from three processing plants located in northern (Mexicali, Baja California $(\mathrm{N}=71)$; Hermosillo, Sonora $(\mathrm{N}=25)$ ), and central Mexico (Guadalajara Jalisco $(\mathrm{N}=16)$ ). Samples were also taken from commercial sales points in southern Mexico (Veracruz, Veracruz $(\mathrm{N}=12)$ ). The samples were classified according to genetic group (GG) in Bos taurus, Bos indicus and commercial crossbreeds, on the basis of the classification used by Méndez et al. (2009) who considered the phenotypic indicators of length and height of hump.

\section{Genotyping}

DNA was isolated from $5 \mathrm{~g}$ lean meat or connective tissue using the commercial kit genomic DNA purification Wizard ${ }^{\circledR}$ (Promega Corp., Madison, WI, USA).

For genotyping, markers CAPN1 316 and CAPN1 4751 were analyzed using an allelic discrimination assay under conditions reported by Parra-Bracamonte et al. (2007). Genotype assignment of each sample was done by ABI Prism 7000 (Real-Time Sequence Detection Software) and it was supported by comparison with samples whose genotype was determined by sequencing.

Analysis of the TG5 marker was achieved by polymerase chain reaction-restriction fragment length polymorphism (PCR-RFLP) assay as reported by Barendse et al. (2004). Briefly, a PCR was done using $100 \mathrm{ng}$ DNA, $3 \mathrm{mM} \mathrm{MgCl}, 0.2 \mathrm{mM}$ dNTP's, $5 \mu \mathrm{M}$ of each primer (TG5U2 5' ggg gat gac tac gag tat gac tg 3' and TG5D1 5' gtg aaa atc ttg tgg agg ctg ta $\left.3^{\prime}\right)$ and $1 \mathrm{U} \mathrm{Taq}^{\circledR}$ DNA Polymerase (Promega Corp.). PCR-profile used in all the assays was: $95^{\circ} \mathrm{C} 5^{\prime}$ ( 2 cycles $), 95^{\circ} \mathrm{C} 45^{\prime \prime}, 62^{\circ} \mathrm{C} 45^{\prime \prime}, 72^{\circ} \mathrm{C} 45^{\prime \prime}\left(5\right.$ cycles decreasing $2^{\circ} \mathrm{C}$ each cycle), $95^{\circ} \mathrm{C} 45^{\prime \prime}, 55^{\circ} \mathrm{C} 45^{\prime \prime}, 72^{\circ} \mathrm{C} 45^{\prime \prime}(25$ cycles $), 72^{\circ} \mathrm{C} 10^{\prime}$. The PCR product was digested with $5 \mathrm{U} \mathrm{MboI}$ enzyme (Promega Corp.) in a final volume of $10 \mu \mathrm{L}$. The digestion pattern was visualized on $20 \%$ acrylamide:Bis (29:1) gels (Sigma-Aldrich).

\section{Meat quality trait analysis}

Meat quality traits included intramuscular fat (IMF), LM content and tenderness LM evaluation with Warner-Bratzler shear force (WBSF) at $24 \mathrm{~h}$ postmortem.

The percentage of fat in the cut muscle was determined by extraction with ethyl ether (AOAC, 2000) and considered as an indicator of the percentage of IMF.

To determine tenderness, LM cuts were thawed, trimmed of connective tissue and fat, and cooked in a dry heat oven to an internal temperature of $70^{\circ} \mathrm{C}$. This was monitored with a thermocouple (Omega Engineering Inc., Stamford, USA) and recorded on a portable thermometer. After cooking, at least 8 pieces of meat were obtained from different parts of sample. Round cores were $2.5 \mathrm{~cm}$ long and $1.27 \mathrm{~cm}$ in diameter, and the test was carried out as proposed by the American Meat Science Association (AMSA, 1995).

The rating scale for tenderness proposed by Belew et al. (2003) was used, establishing samples with $<3.9 \mathrm{~kg}$ WBSF as tender, those with 3.9 to $4.5 \mathrm{~kg}$ as intermediate, and $\geq 4.6 \mathrm{~kg}$ WBSF as tough. 


\section{Statistical analysis}

Genotypic and allelic frequencies for bovine meat for the three markers were analyzed and a Hardy-Weinberg (HW) equilibrium test was done with the GENEPOP 3.4 software (Raymond and Rousset, 1995; Rousset, 2008).

An association test was carried out using a mixed model, including the three genotypes, genetic group, and sampling location as fixed effects. The least squares means and those significant interactions $(\mathrm{P}<0.05)$ were compared with the method of least significant difference using the SAS mixed procedure (2000). For the analysis, the mixed model used was:

$$
\mathrm{Y}_{\mathrm{ijklmn}}=\mu+\mathrm{G}_{\mathrm{i}}+\mathrm{G} 2_{\mathrm{j}}+\mathrm{G} 3_{\mathrm{k}}+\mathrm{S}_{1}+\mathrm{GG}_{\mathrm{m}}+\mathrm{A}_{\mathrm{n}}+\varepsilon_{\mathrm{ijklmn}}
$$

where: $\mathrm{Y}_{\mathrm{ijk} \mid m n}=$ dependent variables (WBSF, IMF), $\mu$ = general means, $\mathrm{G}_{\mathrm{i}}=$ fixed effect of $\mathrm{i}$-th genotype of CAPN1 4751 (TT, CT and CC), $\mathrm{G}_{\mathrm{j}}$ = fixed effect of $\mathrm{j}$-th genotype of CAPN1 316 (GG, GC and CC), G3 ${ }_{k}=$ fixed effect of k-th genotype of TG5 (CC, CT and TT), S = fixed effect of 1-th sampling site, $\mathrm{GG}_{\mathrm{m}}=$ fixed effect of $\mathrm{m}$-th genetic group, $\mathrm{A}_{\mathrm{n}}=$ animal random effect, and $\varepsilon_{\mathrm{ijklmn}}=$ random error.

First-order evaluations, where determined, however, were excluded from the model because they did not show any significance $(\mathrm{P}>0.05)$. In the IMF trait the $\mathrm{S}$ effect was also excluded because it was collinear with GG. Genotypes CAPN1 316 CC and TG5 TT (N $\leq 3)$ were excluded from analysis due to low frequency.

\section{RESULTS}

\section{Genotypic and allelic frequencies for CAPN1 316, CAPN1 4751 and TG5 markers}

Table 1 shows genotypic and allelic frequencies obtained in the population analyzed. CAPN1 316 showed low frequency of the favorable homozygote genotype CAPN1 316 CC (0.03); genetic HW disequilibrium $(\mathrm{P}<0.05)$ was observed due to the high frequency of CAPN1 316 GG genotype (64\%).

\begin{tabular}{|c|c|c|c|c|c|c|}
\hline Marker & Genotype & $\mathrm{N}$ & Genotypic frequency & Allele & Allelic frequency & HW \\
\hline \multirow[t]{3}{*}{ CAPN1 316} & $\mathrm{CC}$ & 3 & 0.03 & $\mathrm{C}$ & 0.19 & $* *$ \\
\hline & GC & 34 & 0.33 & G & 0.81 & \\
\hline & GG & 66 & 0.64 & & & \\
\hline \multirow[t]{3}{*}{ CAPN1 4751} & $\mathrm{CC}$ & 26 & 0.26 & C & 0.49 & NS \\
\hline & CT & 47 & 0.46 & $\mathrm{~T}$ & 0.51 & \\
\hline & TT & 28 & 0.28 & & & \\
\hline \multirow[t]{3}{*}{ TG5 } & TT & 1 & 0.01 & $\mathrm{~T}$ & 0.14 & $* *$ \\
\hline & $\mathrm{TC}$ & 32 & 0.26 & $\mathrm{C}$ & 0.86 & \\
\hline & $\mathrm{CC}$ & 90 & 0.73 & & & \\
\hline
\end{tabular}

HW (Hardy-Weinberg) $=* * \mathrm{P}<0.05 ; \mathrm{NS}=\mathrm{P}>0.05$.

The SNP CAPN1 4751 marker showed balanced distribution among homozygote genotypes ( 0.26 and 0.28 for CAPN1 $4751 \mathrm{CC}$ and TT, respectively); allelic frequencies were similar for both allele variants CAPN1 $4751 \mathrm{C}$ and $\mathrm{T}$, confirming genetic equilibrium of locus. 
Finally, the TG5 marker had a high frequency of the TG5 CC genotype (0.73) and a very low occurrence of TG5 TT $\left(\mathrm{f}_{\mathrm{TT}}=0.01\right)$, so the frequency of the TG5 T allele was due only to the heterozygote carriers $\left(\mathrm{f}_{\mathrm{CT}}=0.26\right)$. HW deviation from equilibrium was confirmed for this locus.

\section{CAPN1 and TG5 marker effects on WBSF and IMF}

\section{Warner Bratzler shear force}

This trait was measured $24 \mathrm{~h}$ after animal slaughter and was obtained as a general mean of $4.080 \pm 1.349 \mathrm{~kg}$. Accordingly to Belew et al. (2003) WBSF criterion, the samples were classified as tender (52\%), intermediate (14\%) and tough (34\%).

Arranged by sampling site, $56 \%$ of Hermosillo samples were in the tender category; on the other hand, Veracruz showed a comparatively lower frequency $(8 \%)$ of the beef in the same category (Figure 1). The latter was confirmed by variance analysis, where sampling site showed significant $(\mathrm{P}=0.0191)$ variation in the WBSF trait (Figure 1). Conversely, the GG effect was not significant $(\mathrm{P}=0.2717)$.

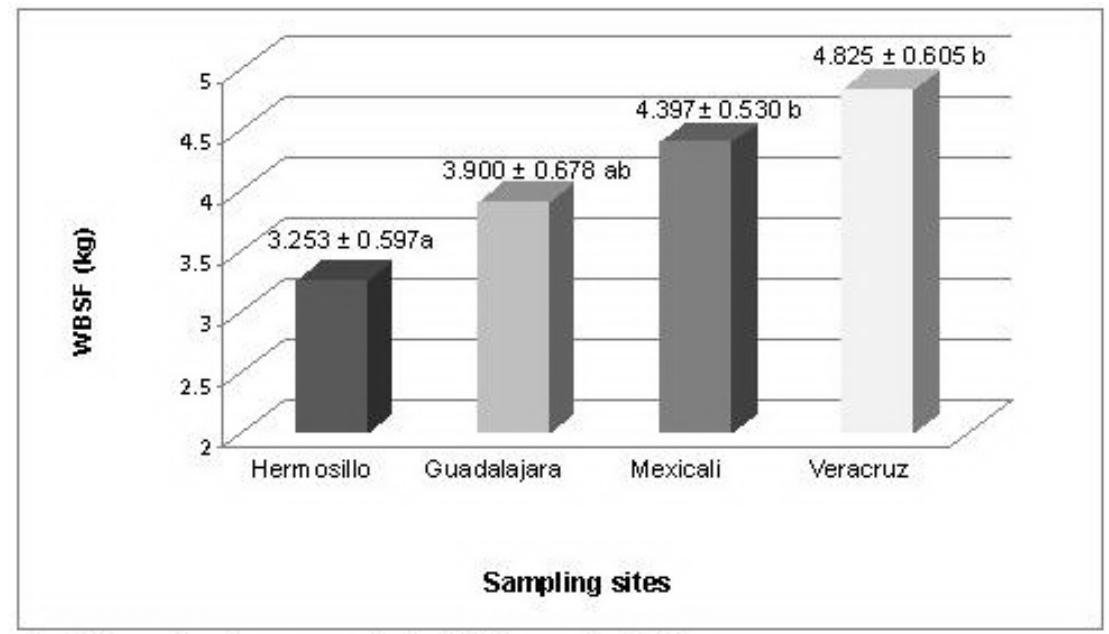

Figure 1. Means \pm standard error of the mean of Warner-Bratzler shear force (WBSF) from beef collected in different sampling sites located in Mexico. a,b. means statistical difference $(\mathrm{P}<0.05)$.

Least square means indicated that Hermosillo had the lowest WBSF $(3.253 \mathrm{~kg}$, unlike the other sampling sites, except for Guadalajara, which was $0.170 \mathrm{~kg}$ higher for WBSF. Veracruz had the toughest beef, with a mean of shear force $1.5 \mathrm{~kg}$ higher than Hermosillo (Figure 1).

Association of SNP markers showed a significant effect of CAPN1 316 on WBSF (P $=0.049$ ), based on a comparison of the only two sufficiently frequent genotypes. Least square means showed favorable effects of the heterozygote CAPN1 316 CG genotype over homozygote CAPN1 $316 \mathrm{GG}$, by being $600 \mathrm{~g}$ softer. No further effects were found for this marker. CAPN1 4751 showed no significant effect $(\mathrm{P}=0.850)$ on WBSF (Table 2$)$. 
Table 2. Least square means \pm standard error of the mean (SEM) of CAPN1 and TG5 marker effects on Mexican beef Warner-Bratzler shear force (WBSF) and intramuscular fat content (IMF).

\begin{tabular}{|c|c|c|c|c|}
\hline \multirow[t]{2}{*}{ Loci } & \multicolumn{2}{|c|}{ WBSF (kg) } & \multicolumn{2}{|c|}{ IMF (\%) } \\
\hline & $\mathrm{N}$ & Mean \pm SEM & $\mathrm{N}$ & Mean \pm SEM \\
\hline CAPN1 $316^{*}$ & & $\mathrm{P}=0.0498$ & & $\mathrm{P}=0.5399$ \\
\hline $\mathrm{CC}$ & - & - & - & - \\
\hline CG & 34 & $3.595 \pm 0.571^{\mathrm{a}}$ & 27 & $6.238 \pm 0.856$ \\
\hline GG & 63 & $4.224 \pm 0.543^{b}$ & 60 & $5.718 \pm 0.791$ \\
\hline CAPN1 4751 & & $\mathrm{P}=0.8524$ & & $\mathrm{P}=0.1583$ \\
\hline $\mathrm{CC}$ & 25 & $4.037 \pm 0.613$ & 21 & $5.126 \pm 0.929$ \\
\hline $\mathrm{CT}$ & 46 & $3.828 \pm 0.549$ & 41 & $5.665 \pm 0.857$ \\
\hline TT & 26 & $3.864 \pm 0.547$ & 25 & $7.144 \pm 0.953$ \\
\hline TG5* & & $\mathrm{P}=0.6889$ & & $\mathrm{P}=0.0074$ \\
\hline TT & - & - & - & - \\
\hline CT & 28 & $3.662 \pm 0.381$ & 25 & $7.634 \pm 1.153$ \\
\hline $\mathrm{CC}$ & 68 & $3.930 \pm 0.300$ & 62 & $4.323 \pm 0.633$ \\
\hline
\end{tabular}

*Statistically different $(\mathrm{P}<0.05)$; a,b means statistical difference $(\mathrm{P}<0.05)$.

\section{Intramuscular fat}

Ether extract content was obtained as an indirect indicator of IMF in transectional rib eye cuts of longissimus dorsi muscle. Overall mean for IMF was $5.235 \pm 2.138 \%$.

Results indicated that GG had a significant effect on IMF $(\mathrm{P}=0.0324)$. Genetic grouping of animals with $B$. taurus inherited background presented least square means of $8.294 \pm 1.163 \%$ for IMF, significantly higher than those animals of $B$. indicus background GG and commercial crossbreeds ( $\mathrm{P}=0.0216$ and 0.0174 , respectively; Table 3$)$.

Table 3. Least square means \pm standard error of the mean of genetic group effect on Mexican beef intramuscular fat content (IMF).

\begin{tabular}{lcc}
\hline Genetic group & N & IMF (\%) \\
\hline B. taurus & 13 & $8.294 \pm 1.163^{\mathrm{a}}$ \\
B. indicus & 15 & $4.310 \pm 1.332^{\mathrm{b}}$ \\
Commercial crossbreeds & 59 & $5.330 \pm 0.691^{\mathrm{b}}$ \\
\hline
\end{tabular}

a,b means statistical difference $(\mathrm{P}<0.03)$.

Regarding the genotype effect, the TG5 locus showed significant effects for its heterozygote TG5 TC. Least square means indicated a higher expression of heterozygotes of $>3 \%$ IMF over TG5 CC homozygotes ( $\mathrm{P}=0.0074)$.

\section{DISCUSSION}

\section{Genotypic and allelic frequencies}

\section{CAPN1 316 and CAPN1 4751}

The low frequency of the CAPN1 $316 \mathrm{CC}$ genotype and a higher proportion of sampled 
animals with the CAPN1 316 GG genotype are similar to studies reported by Page et al. (2004), Van Eenennaam et al. (2007), and Smith et al. (2009) for different genetic groups and breeds in the United States. Similarly, Parra-Bracamonte et al. (2009) reported similar genotypic frequencies for Charolais purebred cattle from northeastern Mexico. However, Parra-Bracamonte et al. (2007), did not find CAPN1 316 CC genotypes but discovered an unexpectedly high frequency of heterozygotes CAPN1 $316 \mathrm{GC}(0.92)$ in a sampled population of Brahman registered cattle, with similar (around 50\%) allelic frequencies.

For CAPN1 4751, frequencies indicated genetic equilibrium promoted by genotypic distribution in the locus (Table 1). Other studies reported similarly balanced frequencies for different beef cattle breed populations in the United States and Mexico (White et al., 2005; Van Eenennaam et al., 2007; Parra-Bracamonte et al., 2009). Conversely, Smith et al. (2009) reported a homozygote deficit for favorable allele CAPN1 $4751 \mathrm{C}$ (as defined by Van Eenennaam et al., 2007) in a Brahman population from Louisiana, USA. Parra-Bracamonte et al. (2007) reported heterozygote excess and equal allelic frequency in a Mexican Brahman population.

Evidence found in the present study and reported elsewhere, strongly suggests that loci allelic frequency variation is a consequence of population management and unaffected genetic flow. Genetic disequilibrium between Calpain markers may support the absent selection for this trait. Although genotype-linked segregation might be misinterpreted, this does not necessarily indicate segregation of favorable alleles (Parra-Bracamonte et al., 2009). The availability of commercial panels for markers associated with quantitative traits could change the reported frequency basis in the future (Quaas et al., 2006), and validation studies (Van Eenennaam et al., 2007) could promote the implementation of markers as selection tools.

In Mexico, the beef market is mainly oriented toward volume production; however, some beef cattle associations are paying attention to new market niche trends. Perhaps in the near future, these tools could be actively used to complement genetic evaluations for growing traits, which are currently used extensively.

\section{TG5}

The present study obtained a very low frequency for the TG5 T allele; several authors have reported low frequencies in this IMF favorable allele in B. indicus cattle (from 0.03 to 0.10 ), as opposed to those reported for Wagyu cattle, characterized by its intramuscular fat known as marbling (Thaller et al., 2003; Barendse et al., 2004; Casas et al., 2005, 2007; Van Eenennaam et al., 2007).

Similar to Calpain markers, genotypic and allelic frequency estimates for TG5 are quite variable among breeds (Van Eenennaam et al., 2007). Predictably, genetic background is a fundamental factor as observed in studies by Smith et al. (2009), who found only three heterozygote individuals (0.004) in a sample of 380 Brahman cattle in contrast with $63 \%$ in allelic frequency in a Wagyu cattle population, as found by Nicol et al. (2001).

When determining allelic frequency and its effect on the quantitative economic traits it is important to know what trait variation is due to locus genotypes, allele substitution effects and the possibility of implementation through assisted selection for genetic improvement (Notter, 2004; Van Eenennaam et al., 2007).

Although a low favorable allele frequency was found for the three markers, undoubtedly it would be possible to increase it, through positive carrier selection. However, this will only be profitable if significant favorable and substantial effects can be guaranteed in specific management systems. 


\section{CAPN1 and TG marker effects on WBSF and IMF}

\section{WBSF}

Currently, the commercially available panels used to diagnose animal predisposition to beef quality traits such as marbling and tenderness are well known (Quaas et al., 2006; Van Eenennaam et al., 2007).

GeneSTAR Quality Grade uses an SNP at the TG gene (Barendse et al., 2004) and an anonymous unpublished polymorphism called M2 (Quaas et al., 2006); GeneSTAR Tenderness comprise polymorphisms at the Calpastatin (CAST) gene (Casas et al., 2006) called T1, and markers CAPN1 316 and CAPN1 4751 (Page et al., 2002; White et al., 2005); IgenityTender GENE comprises the CAPN1 markers previously described and the UoG CAST SNP (Schenkel et al., 2006) as the only difference between panels.

The biological aspects in the nature of polymorphisms have been fully justified (Page et al., 2002; Barendse et al., 2004; White et al., 2005; Casas et al., 2006; Schenkel et al., 2006); however, one aspect of great concern is the validation of marker presumed effects in different breeds and environments (Van Eenennaam et al., 2007).

Validation processes include determination of marker effects on specific quality traits (tenderness and marbling). Therefore, the present study seeks to validate significant marker effects on the beef quality traits of commercial animals.

This study can be taken as a validation assessment of commercially sampled beef, significantly supporting the effect of CAPN1 316 CG genotype on WBSF. The strong relationship in diverse studies in B. taurus and crossbred cattle has been described, pointing strongly to CAPN1 $316 \mathrm{C}$ as a tenderness favorable allele (Page et al., 2002, 2004; Van Eenennaam et al., 2007).

On the other hand, the CAPN1 4751 locus has been associated with beef tenderness in B. taurus, B. indicus, and their reciprocal crossbreeds, making the CAPN1 $4751 \mathrm{C}$ carriers the lowest WBSF animals (White et al., 2005; Casas et al., 2006); however, in the present study this association was not confirmed.

Casas et al. (2005) suggested the low frequency of any genotype as one factor implied the failure of association detection and determination of significant effects on productive traits, especially when there are mechanisms of recessive/dominant action or when the effect of lower frequency genotypes is small. The lack of association identification between CAPN1 4751 locus should not be underrated; Van Eenennaam et al. (2007) suggested higher frequency distribution of alleles and their effects in genotypes did not allow a statistical association. It is possible that further analysis and a larger sample could allow for better validation and characterization for some particular breeds and populations.

The association of CAPN1 316 and CAPN1 4751 markers has been substantially reported regarding tenderness with 7 to 21 days of aging; Page et al. (2004) and White et al. (2005) reported lower WBSF for beef aged 14 days in Simmental and B. taurus $\mathrm{x}$ B. indicus crosses with CAPN1 316 $\mathrm{CC}$ genotypes. Another study reported that Brahman cattle had significant trend effects $(\mathrm{P} \leq 0.0759)$ for WBSF at 7 and 14 days postmortem of heterozygote CAPN1 316 CG genotypes over CAPN1 316 GG genotypes of Brahman cattle (Smith et al., 2009). Similarly, the present study did not include the CAPN1 316 CC genotype in the analysis because of its reduced frequency. Furthermore, methodologically, beef samples studied here were not aged and WBSF was estimated at day $24 \mathrm{~h}$ postmortem.

Taking the literature into account, further analysis is needed to determine mean point es- 
timates for WBSF, and breed and aging effects. Consistently, Smith et al. (2009) and Van Eenennaam et al. (2007) reported the favorable trend of aging on tenderness and association analysis.

However, the effective inclusion of these markers into a genetic improvement program needs additional validation information to characterize the different genetic composition mainly used for slaughter and beef production. Evaluation of the relative impact on selection, where their use in elite nucleus has the potential for dissemination to multiplicative and commercial animals, is important (Parra-Bracamonte et al., 2009). Above all it is worth considering that genetic improvement in Mexico will begin, in theory, with registered cattle where the cost of implementation is more likely to be met.

\section{IMF}

Genetic composition is the one of the most important variation sources for beef marbling (Gao et al., 2007). There is evidence to suggest that B. indicus inheritance breeds have a marked tendency to produce less marbled, less tender beef than European and continental breeds (Sherbeck et al., 1995).

Wheeler et al. (2005) characterized quantity and quality production in several beef cattle breeds, finding Angus cattle to have a higher marbling ability compared with $B$. taurus and crossbred cattle. In the present study, although there was no exact information on sample breed origin, genetic background ( $B$. taurus vs B. indicus) was related to evidence reported. In the same way, Marshall (1994) and Amen et al. (2007) showed that unlike B. indicus and crossbred animals, $B$. taurus cattle had a higher tendency towards marbling.

Crossbreeding has been used to improve productive traits (Bidner et al., 2009). This strategy is carried out in different tropical and subtropical regions in Mexico, where environmental conditions make the use of crossbred cattle with different proportions of $B$. indicus necessary. Thus, the predominant breeds are synthetic, dual-purpose background breeds and commercial crossbreeds of unknown origin. In tropical and subtropical countries, genetic composition is an important factor due to the extensive use of Zebu-derived crossbreeds and synthetic breeds, and to the relatively lower price of beef from these animals.

Phenotypic appearance traits and breed conformation may be used to distinguish and classify the genetic group as proposed by Casas et al. (2005) and Sherbeck et al. (1996) and used by Méndez et al. (2009) as former methodology for this study.

Genetic composition related to marbling is relevant in Latin American countries. Tropical conditions of extreme temperature and low-quality forages promote the need for crossbred cattle; however, genetic constitution is often a limiting factor for international markets, where carcasses are depreciated or classified as low-quality grade where marbling is the main indicator (AMSA, 2002; Trueta, 2003; Riley et al., 2003; Delgado et al., 2005).

Some studies have suggested a link between TG5 and beef marbling; nonetheless, the subjective evaluation of the trait may underestimate significant effects (Barendse et al., 2004). The present study, considering that limitation, explored the indirect objective estimation of intramuscular fact content by extraction of ethyl ether extract (AOAC, 2000) in beef loin cuts.

A marked effect of the TG5 CT genotype ( $\mathrm{P}=0.04)$ on IMF was found (Table 3); allele TG5 $T$ was described as a favorable variant for marbling; previous studies support these findings (Thaller et al., 2003; Barendse et al., 2004). However, Rincker et al. (2006) and Casas et al. (2007) did not find significant effects in B. taurus and B. indicus beef cattle, and only found significant effects of TG5 TT genotype in Wagyu-influenced cattle. Van Eenennaam et al. (2007) and Casas et al. (2007), 
on the other hand, reported trends without significant effects when favorable alleles are present in heterozygote and homozygote genotypes in crossbred Charolais x Angus and other B. indicus cattle.

The exact mechanism for IMF deposition related to TG5 is as yet unknown. It has been suggested that it is likely linked to a mutation that is related to IMF determination (Rincker et al., 2006). The TG5 locus has no significant effect on daily weight gain, weight at slaughter, rib eye fat, rib eye area, among other characteristics, and this may bolster its use in selection programs (Rincker et al., 2006; Casas et al., 2005, 2007), avoiding unexpected pleiotropy effects. Furthermore, Barendse et al. (2004) suggested that it is not necessary to know the parentage relationship or breed because of the strong effect found in the Thyroglobulin gene locus for IMF in heterogeneous populations.

Nevertheless, molecular marker association assessments of quantitative traits depend on several important factors (specific properties of studied populations, environment, sampling size, genotypic frequency). Insufficient data in discovery populations critical for validating supposed associations act as a constant limitation.

\section{CONCLUSIONS}

CAPN1 316 CT and TG5 CT genotypes have significant effects on some beef quality traits and allow the positive characterization of Mexican commercial beef.

Although the present study presents the relative usefulness of CAPN1 316, CAPN1 4751 and TG5 markers, further investigation will build a strong base to improve beef production systems, diagnose defects and identify opportunities. Furthermore, the use of other markers will validate the assessed markers.

\section{REFERENCES}

Amen TS, Herring AD, Sanders JO and Gill CA (2007). Evaluation of reciprocal differences in Bos indicus x Bos taurus backcross calves produced through embryo transfer: II. Postweaning, carcass, and meat traits. J. Anim. Sci. 85: 373-379.

American Meat Science Association (AMSA) (1995). Research Guidelines for Cookery, Sensory Evaluation and Instrumental Tenderness Measurements of Fresh Meat. AMSA \& National Livestock and Meat Board, Chicago.

American Meat Science Association (AMSA) (2002). Meat Evaluation Handbook. American Meat Science Association (AMSA), Champaign.

Association of Official Analytical Chemists (AOAC) (2000). Official Methods of Analysis. AOAC, Washington,

Barendse W (2005). The transition from quantitative trait loci to diagnostic test in cattle and other livestock Aust. J. Exp. Agr. 45: 831-836.

Barendse W, Bunch R, Thomas M, Armitage S, et al. (2004). The TG5 thyroglobulin gene test for a marbling quantitative trait loci evaluated in feedlot cattle. Aust. J. Exp. Agr. 44: 669-674.

Belew JB, Brooks JC, McKenna DR and Savell JW (2003). Warner-Bratzler shear evaluations of 40 bovine muscles. Meat Sci. 64: 507-512.

Bidner TD, Humes PE, Wyatt WE, Franke DE, et al. (2009). Influence of Angus and Belgian Blue bulls mated to Hereford x Brahman cows on growth, carcass traits, and longissimus steak shear force. J. Anim. Sci. 87: 1167-1173.

Casas E, White SN, Riley DG, Smith TP, et al. (2005). Assessment of single nucleotide polymorphisms in genes residing on chromosomes 14 and 29 for association with carcass composition traits in Bos indicus cattle. J. Anim. Sci. 83: 13-19.

Casas E, White SN, Wheeler TL, Shackelford SD, et al. (2006). Effects of calpastatin and micro-calpain markers in beef cattle on tenderness traits. J. Anim. Sci. 84: 520-525.

Casas E, White SN, Shackelford SD, Wheeler TL, et al. (2007). Assessing the association of single nucleotide polymorphisms at the thyroglobulin gene with carcass traits in beef cattle. J. Anim. Sci. 85: 2807-2814.

Delgado EJ, Rubio MS, Iturbe FA, Méndez RD, et al. (2005). Composition and quality of Mexican and imported retail beef in Mexico. Meat Sci. 69: 465-471.

Gao Y, Ran Z, Hu XX and Li N (2007). Application of genomic technologies to the improvement of meat quality of farm animals. Meat Sci. 77: 36-45. 
GeneSTAR (2010). GeneSTAR. Available at [http://www.pfizeranimalgenetics.com.au/sites/PAG/aus/Pages/beef products.aspx]. Accessed June 14, 2010.

Igenity TenderGene (2010). Igenity TenderGene. Available at [http://www.igenity.com/news/pressreleases/ September3-2008-1.aspx]. Accessed June 14, 2010.

Marshall DM (1994). Breed differences and genetic parameters for body composition traits in beef cattle. J. Anim. Sci. 72: $2745-2755$.

Méndez RD, Meza CO, Berruecos JM, Garcés P, et al. (2009). A survey of beef carcass quality and quantity attributes in Mexico. J. Anim. Sci. 87: 3782-3790.

Meuwissen THE and Goddard ME (1996). The use of marker haplotypes in animal breeding schemes. Genet. Sel. Evol. 28: 161-176.

Nicol DC, Armitage SM, Hetzel DJS and Davis GP (2001). Genotype frequencies for GeneSTAR MARBLING ${ }^{\circledR}$ - A DNA based diagnostic test for beef cattle. Proc. Assoc. Adv. Anim. Breed. Genet. 14: 537-540.

Notter DR (2004). Multiple-Trait Selection in a Single-Gene World. In: Proceedings of the Beef Improvement Federation 36th Annual Research Symposium and Annual Meeting, Sioux Falls, SD. Beef Improvement Fed., San Antonio, 26-31.

Page BT, Casas E, Heaton MP, Cullen NG, et al. (2002). Evaluation of single-nucleotide polymorphisms in CAPN1 for association with meat tenderness in cattle. J. Anim. Sci. 80: 3077-3085.

Page BT, Casas E, Quaas RL, Thallman RM, et al. (2004). Association of markers in the bovine CAPN1 gene with meat tenderness in large crossbred populations that sample influential industry sires. J. Anim. Sci. 82: 3474-3481.

Parra-Bracamonte GM, Sifuentes-Rincón AM, Cienfuegos-Rigas EG, Tewold-Medhin A, et al. (2007). Polymorphism in the m-calpain gene of registered Brahman cattle from Mexico. Arch. Latinoam. Prod. Anim. 15: 32-37.

Parra-Bracamonte GM, Sifuentes-Rincón AM, Arellano-Vera W, Almanza-González A, et al. (2009). Three commercialtrait-related genetic markers typification in Charolais cattle: implications for mexican beef cattle production. Rev. Colomb. Cienc. Pecu. 22: 257-266.

Quaas RL, Thallman RM, Van Eenennaam AL, Fernando RL, et al. (2006). Validation of Commercial DNA Test for Quantitative Beef Traits. In: 8th World Congress on Genetics Applied to Livestock Production, August 13-18, Belo Horizonte.

Raymond M and Rousset F (1995). GENEPOP (Version 1.2): population genetics software for exact tests and ecumenicism. J. Hered. 86: 248-249.

Riley DG, Chase CC Jr, Pringle TD, West RL, et al. (2003). Effect of sire on mu- and m-calpain activity and rate of tenderization as indicated by myofibril fragmentation indices of steaks from Brahman cattle. J. Anim. Sci. 81: 2440-2447.

Rincker CB, Pyatt NA, Berger LL and Faulkner DB (2006). Relationship among GeneSTAR marbling marker, intramuscular fat deposition, and expected progeny differences in early weaned Simmental steers. J. Anim. Sci. 84: 686-693.

Rousset F (2008). Genepop'007: a complete re-implementation of the Genepop software for Windows and Linux. Mol. Ecol. Res. 8: 103.

Ruíz A, Sagamaga ML, Salas JM and Mariscal V (2004). Impacto del TLCAN en la Cadena de Valor de Bovinos para Carne. Universidad Autónoma Chapingo, Texcoco.

Schenkel FS, Miller SP, Jiang Z, Mandell IB, et al. (2006). Association of a single nucleotide polymorphism in the calpastatin gene with carcass and meat quality traits of beef cattle. J. Anim. Sci. 84: 291-299.

Sherbeck JA, Tatum JD, Field TG, Morgan JB, et al. (1995). Feedlot performance, carcass traits, and palatability traits of Hereford and Hereford x Brahman steers. J. Anim. Sci. 73: 3613-3620.

Sherbeck JA, Tatum JD, Field TG, Morgan JB, et al. (1996). Effect of phenotypic expression of Brahman breeding on marbling and tenderness traits. J. Anim. Sci. 74: 304-309.

Smith T, Thomas MG, Bidner TD, Paschal JC, et al. (2009). Single nucleotide polymorphisms in Brahman steers and their association with carcass and tenderness traits. Genet. Mol. Res. 8: 39-46.

Statistical Analysis Systems (SAS) (2000). User's Guide: Statistic. Version 6.12. SAS Institute, Cary.

Thaller G, Kuhn C, Winter A, Ewald G, et al. (2003). DGAT1, a new positional and functional candidate gene for intramuscular fat deposition in cattle. Anim. Genet. 34: 354-357.

Trueta SR (2003). Crónica de Una Muerte Anunciada, Impactos del TLC en la Ganadería Bovina Mexicana. In: Memorias del XXVII Congreso Nacional de Buiatría, Junio 12 al 14 Asociación Mexicana de Médicos Veterinarios Especialistas en Bovinos, VillaHermosa, 57-89.

Van Eenennaam AL, Li J, Thallman RM, Quaas RL, et al. (2007). Validation of commercial DNA tests for quantitative beef quality traits. J. Anim. Sci. 85: 891-900.

Wheeler TL, Cundiff LV, Shackelford SD and Koohmaraie M (2005). Characterization of biological types of cattle (Cycle VII): Carcass, yield, and longissimus palatability traits. J. Anim. Sci. 83: 196-207.

White SN, Casas E, Wheeler TL, Shackelford SD, et al. (2005). A new single nucleotide polymorphism in CAPN1 extends the current tenderness marker test to include cattle of Bos indicus, Bos taurus, and crossbred descent. J. Anim. Sci. 83: 2001-2008. 